\title{
Evaluating the Sensitivity of Ecosystems to Soil Salinization in the Manas River Basin
}

\author{
Tianyou Zhang, Ling Wang*, Yan Han \\ School of Science, Shihezi University, Shihezi, 832003, China
}

Received: 28 June 2016

Accepted: 15 October 2016

\begin{abstract}
Based on Landsat 8-OLI (operational land imager) images and field surveys, we mapped soil salinization across seven ecosystems in the Manas River basin (MRB), and two models of soil salinization (namely an index model and a sensitivity model) were constructed on a regional scale and on the scale of a unit. ArcGIS ordinary Kriging interpolation was used to determine the spatial distribution of the sensitivity of each ecosystem to soil salinity. The ecosystems differed markedly in their sensitivity: the grassland ecosystem was the most sensitive and the farmland ecosystem was the least sensitive; the other five ecosystems, in descending order of their sensitivity, were desert, urban, forest, wetland, and shrubland. In terms of area, the ecosystems less sensitive to salinity accounted for $40 \%$ of the total area; those slightly sensitive accounted for approximately $24 \%$; moderately sensitive, $12 \%$; highly sensitive, $14.5 \%$; and extremely sensitive, $9.5 \%$. The extremely sensitive areas were mostly distributed around Lake Manas while the highly sensitive areas were mainly downwind of the lake. The moderately sensitive areas were occupied mainly by the wetlands and grasslands, the slightly sensitive areas by the deserts, and the least sensitive areas by the farmlands.
\end{abstract}

Keywords: soil salinization, ecological sensitivity, Kriging interpolation, Manas River basin

\section{Introduction}

In arid and semi-arid areas, the main cause of land degradation is soil salinization, whether occurring naturally or as a result of human activity [1-3]. With global warming in recent years, soil salinization has become a major concern in regions of low or mid latitudes and a serious ecological problem worldwide [45], and also threatens the ecological security and stability

*e-mail: rain_ling@163.com of the oasis in Xinjiang - a major grain production area in China.

Ecological sensitivity is a reflection of the degree to which the natural environment is disturbed by human activity, and is used as a measure of environmental problems in a regional ecosystem [6]. Evaluating ecological sensitivity has become an important basis for evaluating ecological environments and is an actively pursued topic of research in macro ecology [7]. Currently, scholars in China and the rest of the world conduct such evaluations from two aspects: namely the sensitivity mechanism and the sensitivity of specific ecological processes. The sensitivity mechanism mainly involves ecological sensitivity to such 
problems as water erosion [8], groundwater depletion [9], desertification [10], and soil salinization [11-12], and the specific ecological processes include bio-production [13], the water cycle [14], and the carbon cycle [15]. Field and analog observations and scenario analysis have been used for evaluating the sensitivity of an ecosystem to environmental change and human activity [16].

Different ecosystems and their processes create and maintain a regional life support system that provides the necessary conditions for the survival and development of human beings [17-18]. In the middle and lower reaches of the Manas River basin (MRB), soil salinization is a sensitive ecological mechanism and an effective measure of regional problems related to the ecological environment. Wang et al. [19] established the ecological sensitivity index model by taking advantage of the relationship between land use and salinization and assessed the sensitivity of the ecosystem to salinity in the area around Lake Aibi; Li et al. [20] did the same for an oasis, using the technology of remote sensing and geographical information system (RS/GIS); and Mamat et al. [21] combined multiple factors with the support of GIS and RS to assess the sensitivity of the Weigan-Kuche River delta oasis to soil salinity. However, research on the sensitivity of different ecosystems to soil salinization is limited, which is why the present paper chose to focus on those pockets of MRB that are affected by soil salinization. The study used GIS, $\mathrm{RS}$, and the space model analysis method to calculate the sensitivity index of the sensitivity of different ecosystems to soil salinization and constructed a model of that sensitivity to analyse its spatial distribution to provide a reliable basis for managing regional ecological security and the ecological environment.

\section{Material and Methods}

\section{Study Area}

The study region $\left(43^{\circ} 27^{\prime}-45^{\circ} 21^{\prime} \mathrm{N}, 85^{\circ} 01^{\prime}-86^{\circ} 32^{\prime} \mathrm{E}\right)$ is part of the MRB in northwestern China at the hinterland of the Eurasian continent and lies at the middle northern foot of the Tianshan Mountains and the south bank of Junggar basin, which originates from the snow-clad middle northern Tianshan Mountains [22]. The Manas River basin enjoys a temperate arid continental climate, with annual average temperature of $5-7^{\circ} \mathrm{C}$, annual precipitation of 110-200 mm, and annual potential evaporation of 1,500-2,000 mm. High evaporation and sharp differences between the day temperatures and night temperatures are characteristic features of this dry climate [23]. The river basin is a typical mountain basin system and includes all types of ecosystems.

Since ancient times, MRB has served as a pasture, and since the founding of the People's Republic of China, Xinjiang Production and Construction Corps (XPCC)
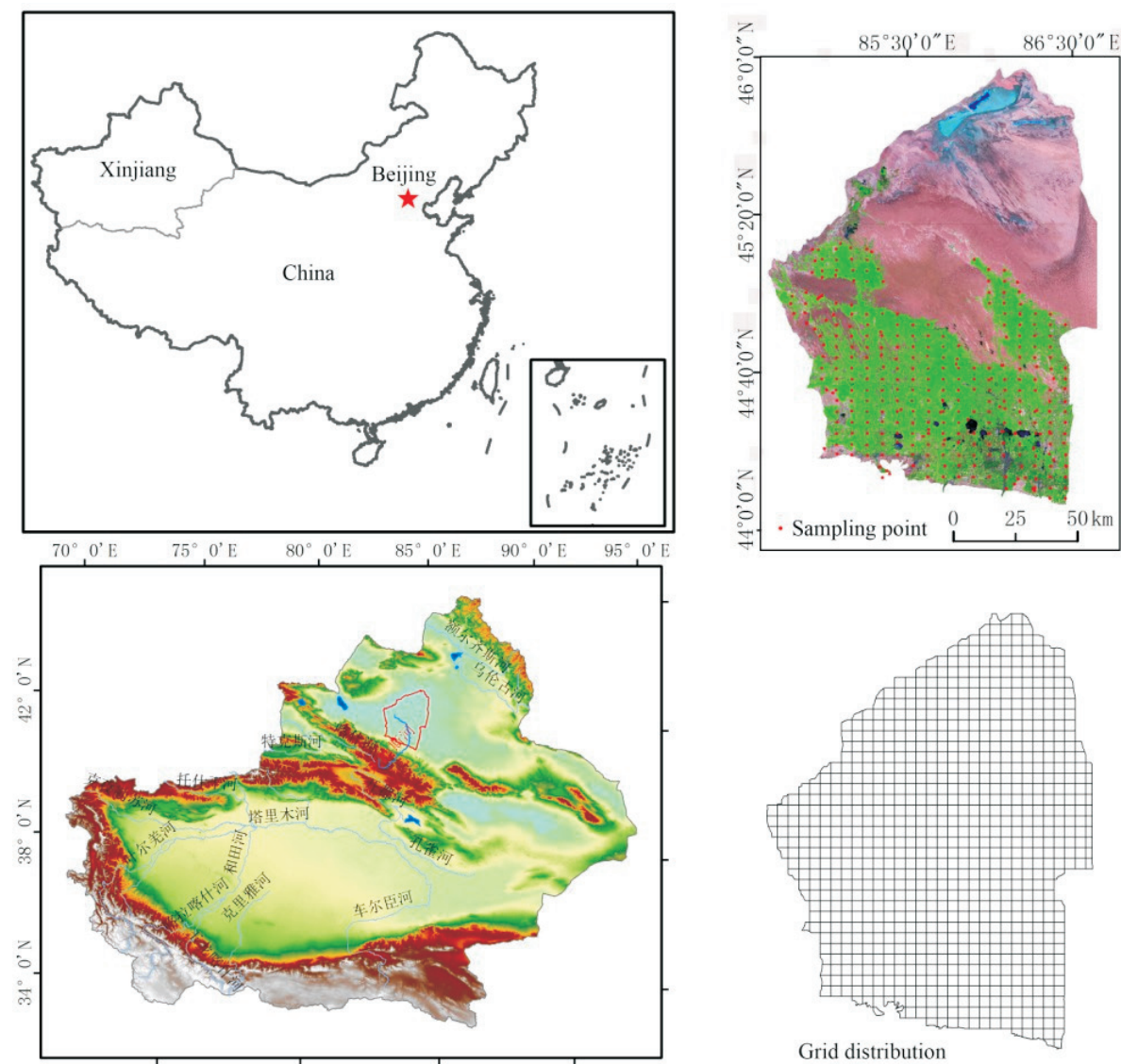

Fig. 1. Study area. 
has been the main force in regional construction to house troops and to open up and develop the wasteland as an important production centre. Although XPCC's achievements have been impressive, they have led to a few serious problems, including overexploitation of water resources, which, in turn, has raised the groundwater level and caused extensive secondary salinization of soil, thereby threatening the regional ecological environment. The present study selected the area from the alluvial plain to Lake Manas, where salinization is a serious problem (Fig. 1).

\section{Data and Processing}

Images from the Landsat 8 operational land imager (OLI) were obtained from the United States Geological Survey (USGS). The surface reflectance in OLI has a resolution of $30 \times 30 \mathrm{~m}$ in seven multispectral bands. The image, acquired for 10 Sept. 2015 (a nearly cloudfree day) covered the entire study area [24]. The image was subjected to geometric correction and radiometric correction [25-26], and spliced and cut as required to represent the chosen study area.

\section{Classification of Ecosystems}

Taking into account the spectrum characteristics of the data from RS images, combining regional climate and relief differentiation characteristics, and referring to the national land coverage classification system, the study area was divided into the following eight types of ecosystems by Class I [27]: forest, bush, grassland, wetland, farmland, urban, desert, and bare land. The classification uses eCognition, a software package, as the platform to carry out automatic classification and interpretation of images, supported by visual check, to obtain the results of classification [28]. Overall precision of more than $85 \%$ is guaranteed. The results are shown in Fig. 2.

\section{Classification of Saline Soils}

A total of 324 locations (each representing a square measuring $25 \mathrm{~m}^{2}$ ) were selected for soil sampling. The samples were collected during June-September 2015. At each sampling location, salinity in the root zone $(0-20 \mathrm{~cm})$ was measured as electrical conductivity of the saturated soil extract using the saturated paste extraction method (U.S. Salinity Laboratory 1954) [30]. The experimental results and features of the sampled area were used for determining the features of soil salinity in images [31]. The salinity classification was based on the geographical system control theory [32], which supervises the classification and combines the decision tree for classification. Combining the digital elevation model (DEM), normalized difference vegetation index (NDVI) [33], and modified normalized difference water index (MNDWI) [34], soil salinity was classified into four categories (Table 1).

\section{Constructing the Soil Salinization Sensitivity Index}

The index of sensitivity of different ecosystems to soil salinity was calculated as follows:

$$
E S_{i}=\sum_{\mathrm{j}=1}^{n} \frac{A_{i j}}{A_{i}} \cdot S_{i j}
$$

...where $i$ is the type of ecosystem, $j$ is the sensitivity level, $n$ is the total number of ecosystems, $E S_{i}$ is the sensitivity index that the type $i$ ecosystem corresponds to, $\mathrm{A}_{i j}$ is the level $j$ of salinization-sensitive area in type $i$ ecosystem, $\mathrm{A}_{i}$ is total area of type $i$ ecosystem, and $\mathrm{S}_{i j}$ is the weight of type $i$ ecosystem compared to sensitivity level $j$.

The regional salinity levels were classified as nonsensitive, slightly sensitive, moderately sensitive, and highly sensitive and were given weights of $1,3,5$, and

Table 1. Four categories of soil salinity and field observations for each, based on soil salinity classification and E C ranges [29].

\begin{tabular}{|c|c|c|c|}
\hline $\begin{array}{l}\text { Category of } \\
\text { soil salinity }\end{array}$ & $\begin{array}{l}\text { EC range } \\
(\mathrm{dS} / \mathrm{m})\end{array}$ & Field observations & Features extraction \\
\hline Non-saline & $<2$ & $\begin{array}{l}\text { No salt crust or cropland affected by soil salinity. } \\
\text { Intensive agriculture and fruit production. } \\
\text { No water-logged areas found. }\end{array}$ & \\
\hline Slightly saline & $2-4$ & $\begin{array}{l}\text { Salt-tolerant species found to be healthy. } \\
\text { Cultivated land under drip irrigation. }\end{array}$ & \\
\hline $\begin{array}{l}\text { Moderately } \\
\text { saline }\end{array}$ & $4-8$ & $\begin{array}{l}\text { Plant community dominated by natural salt-tolerant plants. } \\
\text { No cultivated areas; greater land reclamation activities. }\end{array}$ & \\
\hline Highly saline & $8-16$ & $\begin{array}{l}\text { Plant community dominated by natural salt-tolerant plants. } \\
\text { No cultivated areas; greater land reclamation activities. } \\
\text { Large, bare saline areas and wetlands as a result of waterlog- } \\
\text { ging and raised water table. }\end{array}$ & \\
\hline
\end{tabular}


7, respectively, for normalization processing to get the vectors of the four weights for non-saline land, slightly saline land, moderately saline land, and highly saline land of $0.06,0.19,0.31$, and 0.44 , respectively.

The soil salinization sensitivity index can determine only the sensitivity to salinization of different ecosystems or ecological types; it does not reflect the spatial extent of that sensitivity. To determine the spatial extent of the sensitivity, a sensitivity model, namely $R E S$, was constructed with the following formula:

$$
R E S_{i}=\sum_{i=1}^{n} \frac{A_{i}}{T A} \cdot E S_{i}
$$

...where RES is the unit regional sensitivity, $\mathrm{A}_{i}$ is the area (extent) of the unit-based ecosystem type $I$, TA is the unit's total area, and $\mathrm{ES}_{i}$ is the salinization sensitivity index of ecosystem type $i$.

\section{Spatial Analysis}

Sensitivity to soil salinity can visually reflect the spatial heterogeneity of regional soil salinization sensitivity and reveal unstable areas with interference of salinization. The square unit division method was used for determining the size of every sampling lattice of $5 \mathrm{~km} \times 5 \mathrm{~km}$, with 855 lattices in total, and treats every lattice as a regional unit to calculate its sensitivity soil salinity. From ArcGIS 10.0 geostatistical module [12], the Ordinary Kriging interpolation method was used for carrying out spatial interpolation of the 855 units in the area and then for obtaining the spatial distribution of the sensitivity in the study area [35]

\section{Results and Discussion}

\section{Results and Analysis of Remote Sensing Image Classification}

Table 2 and Fig. 2 clearly show the area and share (proportion) in the total area for each of the different ecosystems in the study and their current spatial distribution. The grassland ecosystem is mainly downstream of MRB; at 4,272.54 $\mathrm{km}^{2}$ it accounts for $20.04 \%$ of the total area. The urban ecosystem consists of urban/rural residential and other built-up areas; at $661.96 \mathrm{~km}^{2}$, it accounts for $3.10 \%$ of the total. The farmland ecosystem, at $7,725.13 \mathrm{~km}^{2}$, accounts for $36.23 \%$, and is found mainly in the midstream of the
Table 3. Extent of saline soils in the Manas River basin in 2015.

\begin{tabular}{|c|c|c|c|c|}
\hline Extent & $\begin{array}{c}\text { Non- } \\
\text { saline }\end{array}$ & $\begin{array}{c}\text { Slightly } \\
\text { saline }\end{array}$ & $\begin{array}{c}\text { Moderately } \\
\text { saline }\end{array}$ & $\begin{array}{c}\text { Highly } \\
\text { saline }\end{array}$ \\
\hline Area $\left(\mathrm{km}^{2}\right)$ & $12,160.07$ & $1,829.40$ & $5,122.18$ & $2,206.01$ \\
\hline Percentage & $57.04 \%$ & $8.58 \%$ & $24.03 \%$ & $10.35 \%$ \\
\hline
\end{tabular}

basin. The forest ecosystem on the banks of the Manas River and also occupying the urban forest belt and a protected forest, at $18.46 \mathrm{~km}^{2}$, accounts for only $0.09 \%$ of the area. The bush ecosystem, at $1,861.80 \mathrm{~km}^{2}$, accounts for $8.73 \%$ of the area and is mainly distributed in the oasis and the transitional area of the Gurbantunggut Desert. The desert ecosystem, mainly in the Gurbantunggut Desert at $6,415.72 \mathrm{~km}^{2}$, accounts for $18.38 \%$ of the area and is distributed along the southern edge of MRB. Lastly, the wetland ecosystem at $366.51 \mathrm{~km}^{2}$ accounts for $30.09 \%$ of the total area and forms the low-lying areas of the delta. Thus four ecosystems, namely farmland, forest, bush, and wetland, account for two-thirds of the total area, cover $14,244.44 \mathrm{~km}^{2}$, and play an active role in the rehabilitation and protection of the regional ecological environment.

The spatial distribution of soil salinity in MRB is shown in Fig. 3, and the statistics are given in Table 3. The data currently available show that in recent years, the area under farmland in MRB has expanded greatly, groundwater has been over-extracted, and the allocation of water resources has been inequitable, aggravating

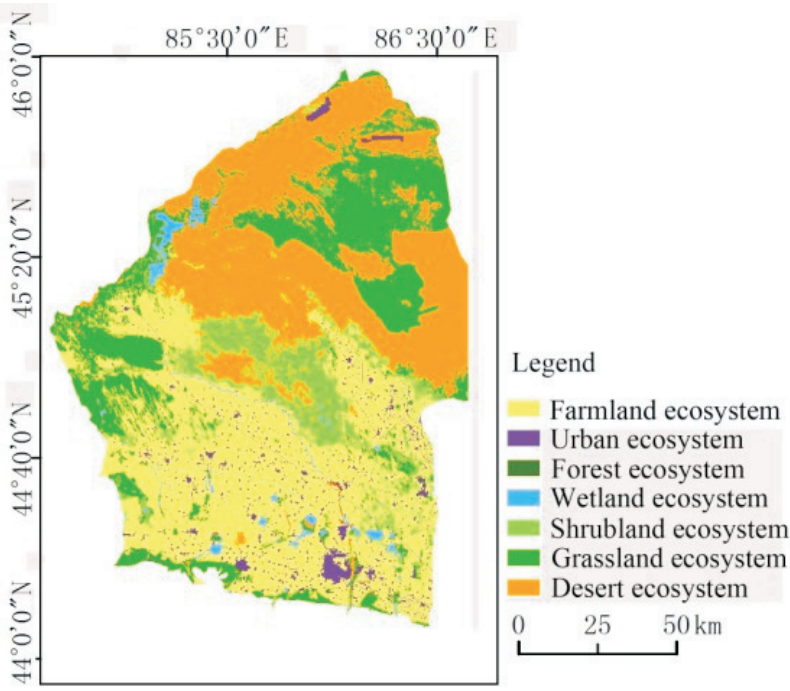

Fig. 2. Distribution of seven ecosystems in the Manas River basin of Xinjiang in 2015.

Table 2. Spatial extent of seven ecosystems in the Manas River basin in 2015.

\begin{tabular}{|c|c|c|c|c|c|c|c|}
\hline Extent & Grassland & Urban & Farmland & Forest & Bush & Desert & Wetland \\
\hline Area $\left(\mathrm{km}^{2}\right)$ & $4,272.54$ & 661.96 & $7,725.13$ & 18.46 & $1,861.80$ & $6,415.72$ & 366.51 \\
\hline Percentage & 20.04 & 3.10 & 36.23 & 0.09 & 8.73 & 30.09 & 1.72 \\
\hline
\end{tabular}




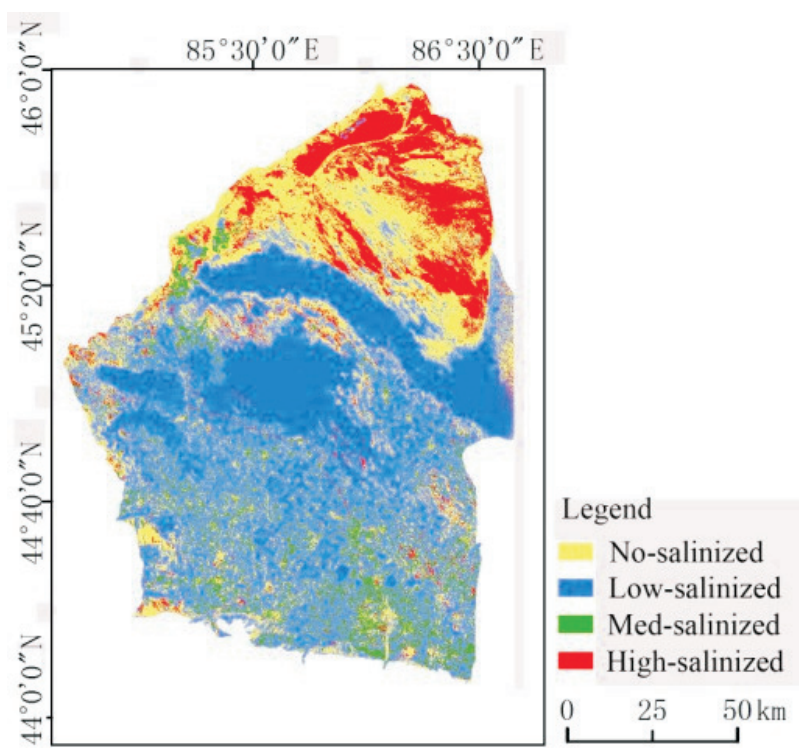

Fig. 3. The classification of saline soils in the Manas River basin of Xinjiang in 2015.

the problem of soil salinity in MRB. Highly saline soil is distributed mainly in the desert around Lake Manas downstream of the study area in regimental farms Nos. 142, 144, 149, and 150, and covers 2,206.01 km², accounting for $10.35 \%$ of the total area. The moderately saline lands are distributed around the highly saline soils and midstream reservoirs. The two categories together cover $7,328.19 \mathrm{~km}^{2}$, accounting for $34.38 \%$ of the total study area. The slightly saline lands are distributed mainly in the irrigated areas of the basin and in the transitional area between oasis and desert. At $1,829.40 \mathrm{~km}^{2}$ they account for $8.58 \%$ of the total area; the corresponding figures for

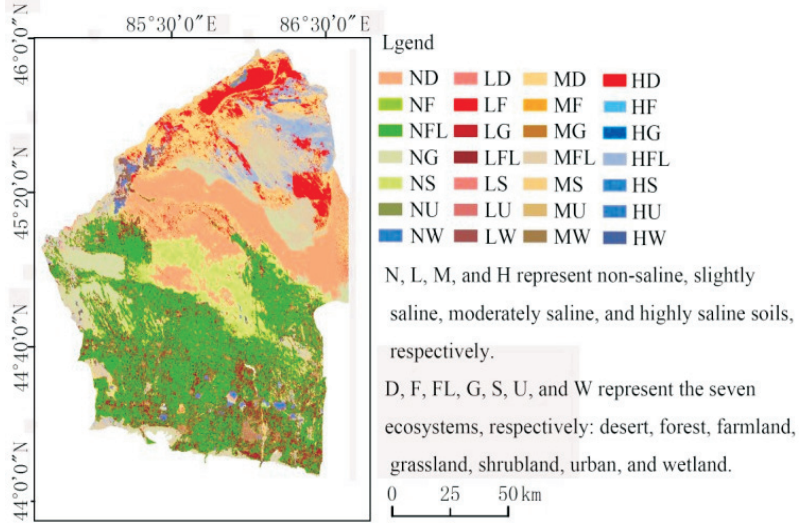

Fig. 4. Distribution of soils differing in salinity in different ecosystems.

the non-saline lands are $12,160.07 \mathrm{~km}^{2}$ and $57.04 \%$. The highly saline and moderately saline soils have a large share but are confined mainly to the southern edge of the study area. The salinity is mainly due to the build-up of the surface layer of saline soil which, in turn, is due to Lake Manas being nearly dry. Therefore, constructing a transitional belt between the farmland ecosystem and the desert ecosystem is particularly important for protecting the farmland.

\section{Overlaying and Analysis of Different Types of Saline Lands in Different Ecosystems}

We used the spatial analysis module in ArcGIS ver. 10.0 for analysing the spatial distribution of soils that differed in their degrees of salinity in different ecosystems (Fig. 3 and Table 4).

Table 4. Extent and distribution of soils of different degrees of salinity in different ecosystems.

\begin{tabular}{|c|c|c|c|c|c|}
\hline \multirow{2}{*}{ Ecosystem } & Extent & Non-saline & Slightly saline & Moderately saline & Highly saline \\
\hline \multirow{3}{*}{ Grassland } & Area $\left(\mathrm{km}^{2}\right)$ & $1,462.07$ & 77.09 & $1,888.45$ & 844.93 \\
\cline { 2 - 6 } & Percentage & 34.22 & 1.80 & 44.20 & 19.78 \\
\hline \multirow{3}{*}{ Urban } & Area $\left(\mathrm{km}^{2}\right)$ & 186.96 & 242.41 & 171.32 & 61.27 \\
\cline { 2 - 6 } & Percentage & 28.24 & 36.62 & 25.88 & 9.26 \\
\hline \multirow{3}{*}{ Bush } & Area $\left(\mathrm{km}^{2}\right)$ & $1,462.43$ & 62.33 & 296.37 & 40.68 \\
\cline { 2 - 6 } & Percentage & 78.55 & 3.35 & 15.92 & 2.18 \\
\hline \multirow{3}{*}{ Desert } & Area $\left(\mathrm{km}^{2}\right)$ & $3,009.56$ & 9.9 & $2,207.12$ & $1,189.15$ \\
\cline { 2 - 6 } & Percentage & 51.59 & 0.15 & 34.40 & 18.53 \\
\hline \multirow{3}{*}{ Farmland } & Area $\left(\mathrm{km}^{2}\right)$ & $5,841.41$ & $1,328.35$ & 502.02 & 53.35 \\
\cline { 2 - 6 } & Percentage & 75.62 & 17.20 & 6.50 & 0.69 \\
\hline \multirow{2}{*}{ Forest } & Area $\left(\mathrm{km}^{2}\right)$ & 8.27 & 6.06 & 3.47 & 0.66 \\
\cline { 2 - 6 } & Percentage & 44.80 & 32.83 & 18.80 & 3.58 \\
\hline \multirow{2}{*}{ Wetland } & Area $\left(\mathrm{km}^{2}\right)$ & 192.28 & 28.75 & 52.39 & 16.49 \\
\cline { 2 - 6 } & Percentage & 52.46 & & 4.50 \\
\hline
\end{tabular}


Table 4 gives the exact area and proportion of soils salinized to different degrees in different ecosystems shown in Fig. 4. In the grassland ecosystem, non-saline and moderately saline lands account for larger areas: $1,462.07 \mathrm{~km}^{2}$ and $1,888.45 \mathrm{~km}^{2}$ or $34.22 \%$ and $44.20 \%$, respectively; in the bush ecosystem, non-saline land covers 1,462.43 $\mathrm{km}^{2}$, accounting for $78.55 \%$; in the desert ecosystem, non-saline land covers $3,009.56 \mathrm{~km}^{2}$, accounting for $51.59 \%$; moderately saline and highly saline lands cover $2,207.12 \mathrm{~km}^{2}$, accounting for $34.46 \%$; in the farmland ecosystem, slightly saline and non-saline lands account for $92.82 \%$; in the forest and the wetland ecosystems, slightly saline lands occupy a larger proportion than that in other ecosystems. Thus, protected forests and farmlands that fringe the forests both contain lands that differ in salinity levels and can be potentially treated for ameliorating salinity, and ecological degradation of farmland and grassland is one of the main causes of the increase in bare lands. Such bare lands are prone to a build-up in salinity, and the ecosystems they support are seriously threatened as a consequence.

\section{Calculating the Soil Salinization Sensitivity Index}

The statistical and calculation functions in ArcGIS ver. 10.0 were used for calculating the area under all types of saline soils in different ecosystems, and Formula (1) was used for calculating sensitivity index $\mathrm{LS}_{i}$ (Table 5) of different ecosystems. The sensitivity index of the different ecosystems was as follows: grassland, 0.24; urban, 0.20; bush, 0.11; desert, 0.22; farmland, 0.10; forest, 0.16; and wetland, 0.15 . The urban ecosystem is highly sensitive because of the construction of salt fields in Lake Manas, which fall under the urban ecosystem as built-up lands; the farmland, desert, forest, and wetland ecosystems showed slightly different sensitivities to salinity - in descending order, the ranking was forest, wetland, desert, and farmland. Given the differing sensitivities, different strategies for dealing with ecological problems are required for different ecosystems.

With a grid consisting of $5 \times 5 \mathrm{~km}$ units as lattices, the total area was divided into 855 unit lattices. To calculate the sensitivity of every lattice unit, the results from Formula (1) were used as inputs for Formula (2) and the Ordinary

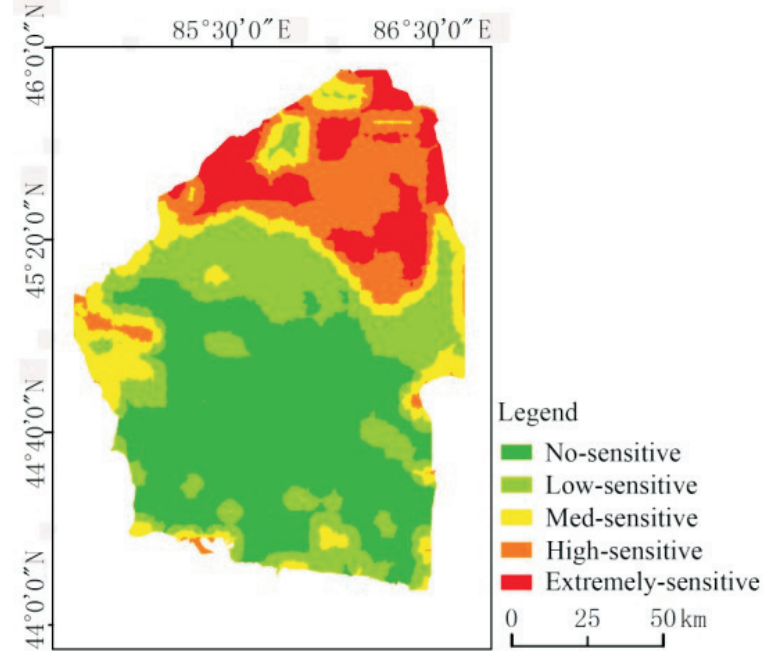

Fig. 5. Spatial distribution of sensitivity to soil salinity in the Manas River basin of Xinjiang in 2015.

Kriging interpolation method in the ArcGIS geostatistical analyst module was used for arriving at the sensitivity index of the centre of each lattice by interpolating. The lattice units were grouped into five categories based on their sensitivity to salinity, namely non-sensitive, slightly sensitive, moderately sensitive, highly sensitive, and extremely sensitive. The spatial distribution of the five categories is shown in Fig. 5 and the exact area and proportion are given in Table 6 .

The extreme sensitivity category covered 2,011.04 $\mathrm{km}^{2}$, accounting for $9.47 \%$ of the total area, and was mainly distributed around Lake Manas. With the lake practically dry, salinity continues to build up, making the ecological environment extremely sensitive and threatening regional ecology. The highly sensitive category covered $3,054.68 \mathrm{~km}^{2}$, accounting for $14.39 \%$ of the total area, and was mainly distributed downstream of the basin and downwind of Lake Manas. The surface layer of salts is continually moved away by wind, changing the ecological environment. The moderately sensitive category covered $2,505.54 \mathrm{~km}^{2}$, accounting for $11.80 \%$ of the total area, and was mainly distributed along the southern edge of Gurbantunggut Desert and the delta of the basin. The slightly sensitive category occurred mainly

Table 5. Soil salinization sensitivity index of different ecosystems.

\begin{tabular}{|c|c|c|c|c|c|c|c|}
\hline & Grassland & Urban & Bush & Desert & Farmland & Forest & Wetland \\
\hline Salinization sensitivity index & 0.24 & 0.20 & 0.11 & 0.22 & 0.10 & 0.16 & 0.15 \\
\hline
\end{tabular}

Table 6. Area and proportion of lattice units under different levels of sensitivity to soil salinity.

\begin{tabular}{|c|c|c|c|c|c|}
\hline & Non-sensitive & Slightly sensitive & Moderately sensitive & Highly sensitive & Extremely sensitive \\
\hline Area $\left(\mathrm{km}^{2}\right)$ & $8,494.98$ & $5,165.67$ & $2,505.54$ & $3,054.68$ & $2,011.04$ \\
\hline Percentage & 40.01 & 24.33 & 11.80 & 14.39 & 9.47 \\
\hline
\end{tabular}


in Gurbantunggut Desert, serving as a shield to block the incursion of saline soils. Lastly, the non-sensitive category was mainly distributed in the midstream oasis region, covering a large area $\left(8,494.98 \mathrm{~km}^{2}\right)$, accounting for $40.01 \%$ of the total. The present study noted that since 2000 , drip irrigation has been popularized, raising the ratio of water resources utilization; the area under farmland area has expanded steadily; and measures to counter salinity have improved markedly.

\section{Conclusion}

The different ecosystems showed a clear demarcation in their spatial distribution. Oasis, the main region for grain production in Xinjiang and an important landuse type or ecosystem in arid areas, covered the largest area within the farmland ecosystem. Lake Manas in the north, with its water resources nearly exhausted and its ecological functions curtailed severely, presents a striking instance of sensitivity to salinity. The bush ecosystem between the desert ecosystem and the farmland ecosystem is a strong shelter to protect the farmland ecosystem. Highly saline and moderately saline soils are distributed mainly around Lake Manas, whereas the slightly saline and nonsaline lands are found mainly in the agricultural region in the midstream.

In descending order of their sensitivity to salinity, the different ecosystems were grassland, desert, urban, forest, wetland, bush, and farmland. The index of the first three ecosystems was higher than the mean value of 0.19 . The sensitivity of the farmland ecosystem, particularly important for grain production in the oasis, is a matter of serious concern, although at present the ecosystem is only weakly sensitive to salinity.

Spatial distribution of the sensitivity in MRB showed marked differences, with extremely sensitive and highly sensitive units distributed mainly around Lake Manas and in highly saline areas; the moderately sensitive units were distributed around the edges of the highly sensitive units; the slightly sensitive units, as the boundary between the non-sensitive and the moderately sensitive units, exerted a strong protective effect on the farmland ecosystem. From the south to the north, the non-sensitive, slightly sensitive, moderately sensitive, highly sensitive, and extremelysensitive sectors stretch one after the other, with clear spatial distinctions.

Considering the spatial distribution of sensitivity to soil salinity in MRB, ameliorative measures should focus on the highly sensitivity areas and should include modifying the pattern of production suitably and reducing the risk of land degradation due to salinization. The southern edge of Gurbantunggut Desert, as a shelter for the farmland ecosystem, should be restored with active measures to protect the ecological environment and prevent further ecological degradation.

The drying up of Lake Manas - almost to the point of disappearance - has led to large-scale and severe salinity, which, aided by wind erosion, keeps spreading to downwind areas. Therefore, appropriate measures should be taken to protect those areas and to maintain the surrounding ecological environment. Such measures include the cultivation of halophytic grasses to reduce wind erosion, planting shelter belts of forest trees around the farmland, using water more efficiently, and arresting the incursion of saline land into farmland. In irrigated areas within the oasis, water should be used scientifically and equitably, organic manures should be applied to improve the physical and chemical properties of soil, and secondary salinization should be prevented - these and related measures can ensure stable development and the ecological safety of the region.

\section{Acknowledgements}

We are grateful to the National Natural Science Foundation of China (NSFC) for financial support (41361073).

\section{References}

1. LI J., PU L., HAN M., ZHOU X. Soil salinization research in china: advances and prospects. J. Geogr. Sci. 24 (5), 943, 2014.

2. HOSSEINI S., KAPPAS M., BODAGHABADI M., CHAHOUKI M., KHOJASTEH R. Comparison of different geostatistical methods for soil mapping using remote sensing and environmental variables in Poshtkouh rangelands, Iran. Pol. J . Environ. Stud. 23 (3), 737, 2014.

3. WANG H. JIA G. Satellite-based monitoring of decadal soil salinization and climate effects in a semi-arid region of China. Adv Atmos Sci. 29 (5), 1089, 2012.

4. WANG J., HUANG X., ZHONG T., CHEN Z. Review on sustainable utilization of salt-affected land. Acta. Geograph. Sin. 66 (5), 673, 2011 [In Chinese].

5. BOUKSILA F, BAHRI A, BERNDTSSON R, PERSSON M, ROZEMA J, VANDER S. Assessment of soil salinization risks under irrigation with brackish water in semiarid Tunisia. Environ. Exp. Bot. 92, 176, 2013.

6. YAN L., XU X., XIE Z. LI H. Integrated assessment on ecological sensitivity for beijing. Acta. Ctaecol. Sin. 29 (6), 3117, 2009 [In Chinese].

7. YOU N., MENG J. Ecological function regionalization and ecosystem management based on the Ecological sensitivity and ecosystem service in the middle reaches of the Heihe river. J. Desert. Res. 37 (1), 1, 2017 [In Chinese].

8. XU H. Assessment of ecological change in soil loss area using remote sensing technology. T. Chinese. Soc. Agr. En. 29 (7), 91, 2013 [In Chinese].

9. LI L., SHI Z., YIN W., ZHU D., SAI NG., CAI C.,WANG G. A fuzzy analytic hierarchy process (fahp) approach to ecoenvironmental vulnerability assessment for the danjiangkou reservoir area, china. Ecol. Model. 220 (23), 3439, 2009.

10. ZHAO M., ZHAO W., JIN T., AN Y., XU H. Land desertification sensitivity evaluation in qinghai lake basin. Chinese. Agr. Sci. B. 28 (32), 237, 2012.

11. SAWUT M., EZIZ M., TIYIP T. The effects of land-use change on ecosystem service value of desert oasis: a case study in ugan-kuqa river delta oasis, China. Can. J. Soil. Sci. 93 (1), 99, 2013. 
12. El B. Geomatics-based soil mapping and degradation risk assessment of Nile delta soils. Pol. J . Environ. Stud. 6 (19), $1123,2010$.

13. LIN X., ZHANG Z., WANG S., HU Y., XU G., LUO C., CHANG X., DUAN J., LIN Q., XU B., WANG Y., ZHAO X., XIE Z. Response of ecosystem respiration to warming and grazing during the growing seasons in the alpine meadow on the tibetan plateau. Aer. Forest. Mteorol. 151 (7), 792, 2011.

14. SALA O., GHERARDI L., PETERS D. Enhanced precipitation variability effects on water losses and ecosystem functioning: differential response of arid and mesic regions. Climatic. Change. 131, 1, 2015.

15. RYAN E., OGLE K., ZELIKOVA T., LECAIN D., WILLIAMS D., MORGAN J., PENDALL E. Antecedent moisture and temperature conditions modulate the response of ecosystem respiration to elevated $\mathrm{CO}_{2}$, and warming. Global. Change. Biol. 21 (7), 2588, 2015.

16. LAGERWALL G., KIKER G., MUÑOZ-CARPENA R., WANG N. Global uncertainty and sensitivity analysis of a spatially distributed ecological model. Ecol. Model. 275, 22, 2014.

17. AMUNDRUD S., SRIVASTAVA D. Drought sensitivity predicts habitat size sensitivity in an aquatic ecosystem. Ecology. 96 (7), 1957, 2015.

18. BARABAS G., PASZTOR L., MESZENA G., OSTLING A. Sensitivity analysis of coexistence in ecological communities: theory and application. Ecol. Lett. 17 (12), 1479, 2014.

19. WANG H., TASHPOLAT T., XIE X., FAN Y., ZHANG F., MAMAT S. Assessment of soil salinization sensitivity for different types of land use in the ebinur lake region in Xinjiang. Progr. Geography. 30 (5), 593, 2011 [In Chinese].

20. LI H., LI X., WANG Y. The monitoring of dynamic changes of soil salinization in the downstream oasis of the kaidu river based on remote sensing technology. Remote. Sensing. Land. 25 (1), 85, 2010 [In Chinese].

21. MAMAT T., TTIYIP T., DING J., ZHANG F. A gis-based assessment on sensitivity of soil salinization in arid areas:a case study of the ugan-kuqa river delta. Resources. Sci. 34 (2), 353, 2012 [In Chinese].

22. FENG Y., LUO G., LU L., ZHOU D., HAN Q., XU W., YIN C., ZHU L., DAI L., LI Y., LI C. Effects of land use change on landscape pattern of the Manas River watershed in Xinjiang, China. Environ. Earth. Sci. 64 (8), 2067, 2013 [In Chinese].

23. ZHANG Q., XU H., FAN Z., YU P., LING H. Artificial oasis evolution and its characteristics in the manas river basin, northern xinjiang region, J. Glaciology. Geocryo. 34 (1), 72,
2012 [In Chinese].

24. ZHU Z., FU Y., WOODCOCK C., OLOFSSON P., VOGELMANN J., HOLDEN C., WANG M., DAI S., YU Y. Including land cover change in analysis of greenness trends using all available Landsat 5, 7, and 8 images: A case study from Guangzhou, China (2000-2014). Remote. Sens. Environ. http://dx.doi.org/10.1016/j.rse. 2016.

25. CHANDER G., MARKHAM B., HELDER D. Summary of current radiometric calibration coefficients for Landsat MSS, TM, ETM+, and EO-1 ALI sensors. Remote. Sens. Environ. 113 (5), 893, 2009.

26. NAZEER M., NICHOL J., YUNG Y. Evaluation of atmospheric correction models and Landsat surface reflectance product in an urban coastal environment. Int. J. Remote. Sens. 35 (16), 6271, 2014.

27. OUYANG Z., ZHANG L., WU B., LI X., XU W., XIAO Y., ZHENG H. An ecosystem classification system based on remote sensor information in China. Actaecol. Sin. 35 (2), 219, 2015 [In Chinese].

28. HU L., CHEN Y., XU Y., ZHAO Y., YU L., WANG J., GONG P. A 30 meter land cover mapping of China with an efficient clustering algorithm CBEST. Sci. China. Earth. Sci. 57, 2293, 2014 [In Chinese].

29. BADRELDIN N., GOOSSENS R. A satellite-based disturbance index algorithm for monitoring mitigation strategies effects on desertification change in an arid environment. Mttlg. Adapt. Strat. Gl. 20 (2), 263, 2015.

30. QIAO M., ZHOU S., LU L., YAN J., SONG P., XU W. Causes and Spatial-Temporal Changes of Soil Salinization in Weigan River Basin, Xinjiang. Progr. Geography. 31 (7), 904, 2012 [In Chinese].

31. ZHANG T., WANG L., LUO C., PENG L. Spatiotemporal change of soil salinization in MRB. Res. Soil. Water. Conse. 23 (1), 1, 2016 [In Chinese].

32. ZHAO C., XU L., WANG C., WANG Y., CHI, C. Studying soil salinity and its relations with microtopography and vegetation at field scale. Future. 22 (4), 1227, 2013.

33. XU H. A study on information extraction of water body with the modified normalized difference water Index (MNDWI). J. Remote Sens. 9 (5), 589, 2005 [In Chinese].

34. SCUDIERO E., SKAGGS T., CORWIN D. Regional-scale soil salinity assessment using Landsat ETM + canopy reflectance. Remote. Sens. Environ. 169, 335, 2015.

35. PAN D., JIA H., YUAN Y. A GIS-based ecological safety assessment of Wushen Banner, China. Hum. Ecol. Risk. Assess. 21 (2), 297, 2015. 